\title{
miR-515-5p inhibits the proliferation, migration and invasion of human breast cancer cells by targeting CBX4
}

\author{
LIU-JING WEN $^{1 *}$, YUE-SHENG WANG $^{2^{*}}$ and PEI-YI TAN ${ }^{3}$ \\ ${ }^{1}$ Department of Pharmacy, Tianjin Medical University Cancer Institute and Hospital, National Clinical Research Center for \\ Cancer, Key Laboratory of Cancer Prevention and Therapy, Tianjin's Clinical Research Center for Cancer, Tianjin 300060; \\ ${ }^{2}$ Department of Dentistry, Second Hospital Affiliated to Tianjin Medical University, Tianjin 300211; \\ ${ }^{3}$ Department of Pharmacy, First Teaching Hospital of \\ Tianjin University of Traditional Chinese Medicine, Tianjin 300193, P.R. China
}

Received July 10, 2020; Accepted July 30, 2021

DOI: $10.3892 /$ etm.2021.10763

\begin{abstract}
RNA (miR)-515-5p has been previously suggested to function as a tumor suppressor in various types of human cancer. Therefore, the role of miR-515-5p in breast cancer (BC) was explored in the present study. A series of assays were performed to study the function of miR-515-p in BC cells, including Cell Counting Kit-8, TUNEL, flow cytometric and colony formation to detect cell viability and apoptosis, wound healing and Transwell assays to measure cell motility. In addition, reverse transcription quantitative PCR and western blot analysis were used to assess miR-515-5p, CBX4, Cox-2, MMP2, MMP9, CDK2, p21 and Cyclin D1 respectively. Bioinformatics and dual-luciferase reporter assays were used to analyze the target genes of miR-515-5p, which confirmed the direct binding between miR-515-5p and polycomb chromobox 4 (CBX4). It was found that the expression of miR-515-5p is lower in BC cells compared with that in normal breast cells (MCF10A). Overexpression of miR-515-5p using the miR-515 mimic was found to reduce cell viability, facilitate cell apoptosis, inhibit cell proliferation and arrest cell cycle progressio at $\mathrm{G}_{1}$ phase. In addition, miR-515-5p overexpression could inhibit cell migration and invasion, whilst decreasing the expression levels of prostaglandin-endoperoxide synthase 2 ,
\end{abstract}

Correspondence to: Ms. Liu-Jing Wen, Department of Pharmacy, Tianjin Medical University Cancer Institute and Hospital, National Clinical Research Center for Cancer, Key Laboratory of Cancer Prevention and Therapy, Tianjin's Clinical Research Center for Cancer, 1 West Huan-Hu Road, Ti Yuan Bei Street, Tianjin 300060 , P.R. China

E-mail: ddian2001@163.com

${ }^{*}$ Contributed equally

Abbreviations: CCK-8, Cell Counting Kit-8; CBX4, polycomb chromobox 4; BC, breast cancer; miRNAs/miRs, microRNAs

Key words: microRNA-515-5p, polycomb chromobox 4, human breast cancer
MMP2 and MMP9 proteins. In addition, miR-515-5p overexpression could reduce the expression levels of $\mathrm{CBX} 4$ in MCF7 and ZR-75-30 cells. By contrast, overexpression of CBX4 reversed the effects of the miR-515-5p mimic transfection on cell proliferation, migration and invasion in MCF7 and ZR-75-30 cells. In combination, these results suggest that miR-515-5p inhibits BC cell proliferation, migration and invasion by directly targeting $\mathrm{CBX} 4$.

\section{Introduction}

Breast cancer (BC) is one of the most common types of cancer that affects women worldwide (1). In China, 304,000 cases of female BC and 70,000 deaths were recorded in 2015 (2). A number of factors are involved in the development and promotion of breast malignancy, where the most of which involve changes in the expression profile of microRNAs (miRNAs/miRs) $(3,4)$.

miRNAs are non-coding RNAs that are 21-24 nucleotides in length and post-transcriptionally regulate gene expression by binding to the $3^{\prime}$ untranslated regions (UTR) of their mRNA targets (5). Previous studies have demonstrated that miRNAs can regulate an array of signaling pathways, thereby negatively (6) or positively (7) affecting tumorigenesis and various aspects of cancer progression. Particularly in BC, Kim et al (8) revealed that the stable inhibition of miR-155 can reduce tumor growth by decreasing glucose metabolism through the phosphoinositide-3-kinase regulatory subunit 1-pyruvate dehydrogenase complex kinase/AKT-forkhead box O3a-cMYC axis. Shao et al (9) demonstrated that the plasma level of miR-200a was associated with BC staging at the time of surgery, where high levels of miR-210 expression was associated with internal organ metastasis (liver, lung and brain). Therefore, to promote the application of miRNAs in $\mathrm{BC}$ diagnosis, treatment and prognosis prediction, deeper understanding into the targets and underlying regulatory mechanisms of miRNAs is of great importance.

miR-515-5p was first detected to be a placenta-specific miRNA present in the maternal circulation (10). Previously, miR-515-5p was found to be differentially expressed in prostate cancer tissues, hepatocellular adenomas and normal 
tissues (11,12). In addition, knockdown miR-515-5p was reported to promote non-small cell lung cancer cell survival and metastasis and miR-515-5p were downregulated in the C-X-C motif chemokine ligand 6 (13). These previous observations suggest that miR-515-5p can be used as a biomarker for the prognosis of patients with cancer and possibly serve as a therapeutic target for cancer.

However, in BC, the role of miR-515-5p is unclear; the present study therefore investigated the function of miR-515-5p in $\mathrm{BC}$.

\section{Materials and methods}

Cell lines. The human BC cell lines (MCF7, ZR-75-30, MDA-MB-231 and SKBr-3) and the normal breast cell line (MCF10A) were obtained from the American Type Culture Collection. MCF7 cells were cultured in modified Eagle's medium (cat. no. 30030; Thermo Fisher Scientific, Inc.) supplemented with $1.5 \mathrm{~g} / 1 \mathrm{NaHCO}_{3}$ (Merck KGaA), 10\% FBS (Thermo Fisher Scientific, Inc.), $100 \mathrm{U} / \mathrm{ml}$ penicillin and $100 \mathrm{mg} / \mathrm{ml}$ streptomycin at $37^{\circ} \mathrm{C}$ with $5 \% \mathrm{CO}_{2}$. MDA-MB-231 and MCF10A cells were cultured in DMEM (cat. no. 11965092; Thermo Fisher Scientific, Inc.) supplemented with $10 \%$ FBS, $100 \mathrm{U} / \mathrm{ml}$ penicillin and $100 \mathrm{mg} / \mathrm{ml}$ streptomycin at $37^{\circ} \mathrm{C}$ with 5\% CO $\mathrm{CO}_{2}$. ZR-75-30 and SKBr-3 cells were maintained in RPMI-1640 medium (cat. no. 31870082, Thermo Fisher Scientific, Inc.) supplemented with $10 \%$ FBS, $100 \mathrm{U} / \mathrm{ml}$ penicillin and $100 \mathrm{mg} / \mathrm{ml}$ streptomycin at $37^{\circ} \mathrm{C}$ with $5 \% \mathrm{CO}_{2}$.

Cell transfection. miR-515-5p mimic (UUCUCCAAAAGA AAGCACUUUCUG), NC mimic (UACUGAGAGACAUAA GUUGGUC), pcDNA3.1-chromobox 4 (CBX4) and their respective negative controls ( $\mathrm{NC}$ mimic and $\mathrm{Lv}-\mathrm{NC}$ ) were designed and obtained from Shanghai GenePharma Co., Ltd. Cell transfection was performed on MCF7 or ZR-75-30 cells using X-Porator H1 (cat. no. EBXP-H1, Etta Biotech Co. Ltd.), according to the manufacturer's protocol. Briefly, the MCF7 and ZR-75-30 cells were collected and resuspended in the electroporation buffer at $270 \mathrm{mOsm}$ osmolarity, $0.1 \mathrm{~S} / \mathrm{m}$ conductivity (Etta Biotech Co., Ltd.). The cell concentration was then adjusted to $6 \times 10^{5}$ cells/ml along with mixed $150 \mathrm{nM}$ miRNA mimics and/or $1 \mathrm{mg} / \mathrm{ml}$ plasmid. A total of $100 \mu \mathrm{l}$ cell suspension mixed with RNAs was then added into a $0.4 \mathrm{~mm}$ cuvette and used Matrix needle electrodes for gene transfection using the operator H1. The electroporation device was operated at a direct current square wave with a $180-\mathrm{V}$ voltage, $4 \mathrm{nA}, 500-\mu \mathrm{sec}$ duration, $1-\mathrm{sec}$ intervals and three pulses at room temperature Following electroporation, the cells were diluted to appropriate concentrations in MEM supplemented with $1.5 \mathrm{~g} / 1 \mathrm{NaHCO}_{3}, 10 \% \mathrm{FBS}$ and seeded into appropriate cell culture plates at $37^{\circ} \mathrm{C}$ with $5 \% \mathrm{CO}_{2}$, for use in further assays at $24 \mathrm{~h}$ post-electroporation.

miRNAs and mRNA expression. Total RNA from the cells was isolated using the TRIzol ${ }^{\circledR}$ reagent (Thermo Fisher Scientific, Inc.) according to the manufacturer's protocols. MicroRNA levels were measured using TaqMan ${ }^{\mathrm{TM}}$ MicroRNA Reverse Transcription kit (cat. no. 4366596; Thermo Fisher Scientific, Inc.). The conditions for RT were $16^{\circ} \mathrm{C}$ for $30 \mathrm{~min}, 42^{\circ} \mathrm{C}$ for $30 \mathrm{~min}$ and $85^{\circ} \mathrm{C}$ for $5 \mathrm{~min}$ to terminate the reaction.
TaqMan 2X Fast Universal PCR Master Mix (cat. no. 4367846; Thermo Fisher Scientific, Inc.). The thermocycling conditions were $95^{\circ} \mathrm{C}$ for $20 \mathrm{sec}$, followed by 40 cycles of $95^{\circ} \mathrm{C}$ for $1 \mathrm{sec}$ and $60^{\circ} \mathrm{C}$ for $20 \mathrm{sec}$. The sequence-specific forward primers for mature miR-515-5p and the U6 internal control were 5'-TTC TCCAAAAGAAAGCACTTTCTG-3' and 5'-CTCGCTTCG GCAGCACA-3', respectively. The reverse primer was the universal reverse primer: 5'-GTGCAGGGTCCGAGGT-3'.

To analyze mRNA expression, both cDNA conversion and qPCR amplification were performed using High-Capacity cDNA Reverse Transcription kit (cat. no. 4368813) at $25^{\circ} \mathrm{C}$ for $10 \mathrm{~min}, 37^{\circ} \mathrm{C}$ for $120 \mathrm{~min}$, and heated at $85^{\circ} \mathrm{C}$ for $5 \mathrm{~min}$ and Fast SYBR ${ }^{\circledR}$-Green Master mix (cat. no. 4385614; both from Thermo Fisher Scientific, Inc.). The thermocycling conditions were $95^{\circ} \mathrm{C}$ for $20 \mathrm{sec}$, followed by 40 cycles of $95^{\circ} \mathrm{C}$ for $1 \mathrm{sec}$ and $60^{\circ} \mathrm{C}$ for $20 \mathrm{sec}$, respectively, according to the manufacturer's protocols. Primers for CBX4 were forward, 5'-TGG AGTATCTGGTGAAATGGA-3' and reverse, 5'-ACGACG GGCAAAGGTAGGCAC-3'. Primer for $\beta$-actin were forward, 5'-GTGGGGCGCCCCAGGCACCAGGGC-3' and reverse, 5'-CTCCTTAATGTCACGCACGATTTC-3'.

Cell viability assay. Cell Counting Kit-8 (CCK-8; cat. no. C0037, Beyotime Institute of Biotechnology) colorimetric assay was used to measure cell viability. Briefly, following transfection, MCF7 or ZR-75-30 cells were seeded into 96-well plates with $1 \times 10^{4}$ cells/well. After $0,24,48$ and $72 \mathrm{~h}$ cultured at $37^{\circ} \mathrm{C}$ with $5 \% \mathrm{CO}_{2}$, the supernatant was removed before $100 \mu \mathrm{l}$ MEM or DMEM containing $10 \mu \mathrm{l}$ CCK- 8 was added into each well for $3 \mathrm{~h}$ of incubation at $37^{\circ} \mathrm{C}$. A plate reader (Thermo Multiskan MK3 spectrophotometer; Thermo Fisher Scientific, Inc.) was used to measure absorbance at $450 \mathrm{~nm}$. The optical density value was determined and used to construct a growth curve to assess cell viability.

Colony formation assay. MCF7 or ZR-75-30 cells were seeded into $10-\mathrm{cm}$ dishes $\left(1 \times 10^{3}\right.$ cells/plate) following transfection. The cells were then maintained in complete culture medium (MEM or RPMI-1640, respectively) for another 21 days at $37^{\circ} \mathrm{C}$ with $5 \% \mathrm{CO}_{2}$. Finally, the cells were fixed in $4 \%$ paraformaldehyde at $4^{\circ} \mathrm{C}$ for $30 \mathrm{~min}$ and stained with Giemsa dye at $25^{\circ} \mathrm{C}$ for $30 \mathrm{~min}$. Images of cells were captured by a camera, and the number of clones visible by eye was calculated.

TUNEL assay. After $24 \mathrm{~h}$ of transfection, MCF7 or ZR-75-30 cells were fixed with $4 \%$ paraformaldehyde and apoptosis was detected using a TUNEL assay, as recommended in the ApopTag ${ }^{\circledR}$ Plus Peroxidase In Situ Apoptosis kit (cat. no. S7101; Merck KGaA). Briefly, the cells were fixed with $4 \%$ paraformaldehyde for $30 \mathrm{~min}$ at room temperature and permeabilized with $0.1 \%$ Triton $\mathrm{X}-100$ in $0.1 \%$ sodium citrate for $2 \mathrm{~min}$ at $4^{\circ} \mathrm{C}$. The cells were then incubated with $1 \%$ TdT enzyme in a humidified atmosphere at $37^{\circ} \mathrm{C}$ for $90 \mathrm{~min}$. Subsequently, they were stained with DAPI at a final concentration of $4 \mu \mathrm{g} / \mathrm{ml}$ at $4^{\circ} \mathrm{C}$ for $10 \mathrm{~min}$. Finally, the cells were observed under a fluorescence microscope (200x, CKX53; Olympus). An average of 10 random fields with 100-200 nuclei per field was analyzed.

Flow cytometry. The effect of miR-515-5p on the cell cycle was measured by flow cytometry, as previously described (14). 
Briefly, MCF7 or ZR-75-30 cells were harvested and fixed with $4 \%$ paraformaldehyde for $30 \mathrm{~min}$ at $4^{\circ} \mathrm{C}$. The cells were then incubated with RNase $(50 \mu \mathrm{g} / \mathrm{ml})$ and PI $(50 \mu \mathrm{g} / \mathrm{ml}$; Thermo Fisher Scientific, Inc.) for $30 \mathrm{~min}$ at room temperature. Next, cell cycle profile was measured using a flow cytometry system (BD Accuri C6; BD Biosciences) and the relative ratios of the $\mathrm{G}_{0} / \mathrm{G}_{1}, \mathrm{~S}$ and $\mathrm{G}_{2} / \mathrm{M}$ phases were analyzed by FlowJo V10 software (FlowJo LLC).

Wound healing assay. Wound healing assay was performed to study the migration of MCF7 and ZR-75-30 cells as previously described (15). Briefly, 5x105 MCF7 or ZR-75-30 cells were seeded into each well of a six-well plate. Following transfection for $24 \mathrm{~h}$, a wound was made using a 100- $\mu$ l pipette tip. Following culture in MEM supplemented with $1.5 \mathrm{~g} / 1 \mathrm{NaHCO}_{3}$, $10 \% \mathrm{FBS}, 100 \mathrm{U} / \mathrm{ml}$ penicillin and $100 \mathrm{mg} / \mathrm{ml}$ streptomycin at $37^{\circ} \mathrm{C}$ with $5 \% \mathrm{CO}_{2}$ for another $48 \mathrm{~h}$, the wound recovery area was photographed under a light microscope (200x magnification; CKX41, Olympus) at 0 and $48 \mathrm{~h}$, and evaluated by Image software (version 1.8.0; NIH).

Transwell assay. MCF7 or ZR-75-30 cells were seeded into the upper chamber with $5 \times 10^{5}$ cells containing MEM or DMEM. By contrast, $10 \%$ FBS and complete culture medium were added to the lower chamber. The cells were then cultured for $\sim 48 \mathrm{~h}$ at $37^{\circ} \mathrm{C}$ with $5 \% \mathrm{CO}_{2}$. Next, the cells in the lower chamber were fixed with $4 \%$ paraformaldehyde for $30 \mathrm{~min}$ at $4^{\circ} \mathrm{C}$ and stained with $5 \%$ crystal violet at $4^{\circ} \mathrm{C}$ for $30 \mathrm{~min}$. Finally, cells were photographed under a light microscope (x100 magnification; cat. no. CKX41; Olympus) and counted in five randomly selected microscope fields.

Dual-luciferase reporter assay. The complementary sequences between miR-515-5p and CBX4 were predicted using Starbase (starbase.sysu.edu.cn/), MCF7 or ZR-75-30 cells were co-transfected with $0.24 \mu \mathrm{g}$ of the CBX4-wild-type (WT) or CBX4-mutant (Mut) 3'UTR and pmiRGLO DualLuciferase Vector were designed and obtained from Shanghai GenePharma Co., Ltd. together with 40 nM miR-515-5p mimic or NC mimic using cell electroporation system operator H1, following the manufacturer's protocols. In addition, $0.05 \mu \mathrm{g}$ Renilla luciferase expression plasmid was transfected into the cells as a reference control. Subsequently, $48 \mathrm{~h}$ after transfection, the cells were collected to measure Firefly and Renilla luciferase activities using the Dual-luciferase reporter assay system (cat. no. E1910; Promega Corporation). The relative luciferase activity was calculated as the ratio of Firefly and Renilla luciferase activities.

Western blot analysis. MCF7 or ZR-75-30 cells were harvested using RIPA lysis buffer (P0013B; Beyotime Institute of Biotechnology) and quantified by BCA assay. The total protein $(40 \mu \mathrm{g})$ was then separated on $12 \%$ SDS-PAGE and transferred onto PVDF membranes (EMD Millipore) using a MiniGenie blotting system (Bio-Rad Laboratories, Inc.). Next, the membranes were blocked with TBS-1\% Tween-20 (TBST) containing 1\% skim milk powder for $1 \mathrm{~h}$ at room temperature and then incubated with rabbit monoclonal antibodies (Cell Signaling Technology, Inc.) against human prostaglandin-endoperoxide synthase 2 (Cox-2; cat. no. 12282T; dilution, 1:1,000), MMP2 (cat. no. 40994S; dilution, 1:1,000), MMP9 (cat. no. 13667S; dilution, 1:1,000), cyclin D1 (cat. no. 55506S; dilution, 1:1,000) cyclin dependent kinase 2 (CDK2; cat. no. 2546S; dilution, 1:1,000), proliferating cell nuclear antigen (PCNA; cat. no. 13110S; dilution, 1:1,000), $\beta$-actin (cat. no. 4970T; dilution, 1:1,000) and CBX4 (cat. no. 30559; dilution, 1:2,000) at $4^{\circ} \mathrm{C}$ overnight. Following washing with TBST, the membranes were incubated with goat anti-rabbit secondary antibodies (cat. no. 5127; dilution, 1:10,000; Cell Signaling Technology, Inc.) for $1 \mathrm{~h}$ at room temperature. Finally, the protein brands were visualized with an enhanced chemiluminescence system (P0018FS; Beyotime Institute of Biotechnology) and semi-quantified with ImageJ software (version 1.46; National Institutes of Health).

Statistical analysis. All experiments were performed in triplicate. GraphPad Prism (version 6.01 for Windows; GraphPad Software, Inc.) statistical software was used to perform the statistical analysis. One-way-ANOVA (parametric) followed by Tukey's post hoc test was used to compare the significant differences between groups. $\mathrm{P}<0.01$ was considered to indicate a statistically significant difference.

\section{Results}

miR-515-5p inhibits cell proliferation of MCF7 and ZR-75-30 cells. To confirm if miR-515-5p participates in BC progression, its expression level in BC cell lines MCF7, ZR-75-30, MDA-MB-231, SKBr-3 and the normal breast cell line MCF10A was compared using RT-qPCR. The results showed that the expression of miR-515-5p in human BC lines was significantly lower compared with that in the normal breast cell line $(\mathrm{P}<0.01$; Fig. 1A).

To evaluate the possible effects of miR-515-5p expression on BC progression, MCF7 and ZR-75-30 cells were transfected with miR-515-5p or NC mimics. RT-qPCR results showed that transfection with the miR-515-5p mimic could significantly upregulate miR-515-5p expression in MCF7 and ZR-75-30 cells compared with that in cells transfected with the $\mathrm{NC}$ mimic $(\mathrm{P}<0.01$; Fig. 1B). In addition, CCK-8 assay data showed that miR-515-5p mimic transfection could significantly reduce the viability of MCF7 and ZR-75-30 cells compared with that in cells transfected with the NC mimic $(\mathrm{P}<0.01$; Fig. 1C). Colony formation assay results revealed that transfection with the miR-515-5p mimic significantly reduced the proliferation of MCF7 and ZR-75-30 cells ( $\mathrm{P}<0.01$; Fig. 1D). In conclusion, these data suggest that miR-515-5p overexpression could inhibit BC cell proliferation.

miR-515-5p facilitates cell apoptosis and induces cell cycle arrest at the $G_{0} / G_{1}$ phase in MCF7 and ZR-75-30 cells. The regulation of apoptosis and cell cycle arrest has been found to play an important role in cell proliferation (13). To reveal the mechanism of miR-515-5p in BC cell proliferation, TUNEL and flow cytometric assays were performed to detect the potential effects of miR-515-5p on cell apoptosis and cell cycle progression. First, results from the TUNEL assay indicated that miR-515-5p mimic transfection could significantly facilitate MCF7 and ZR-75-30 cell apoptosis compared with that in cells transfected with the NC mimic $(\mathrm{P}<0.05$ and $\mathrm{P}<0.01$; Fig. 2A). 
A
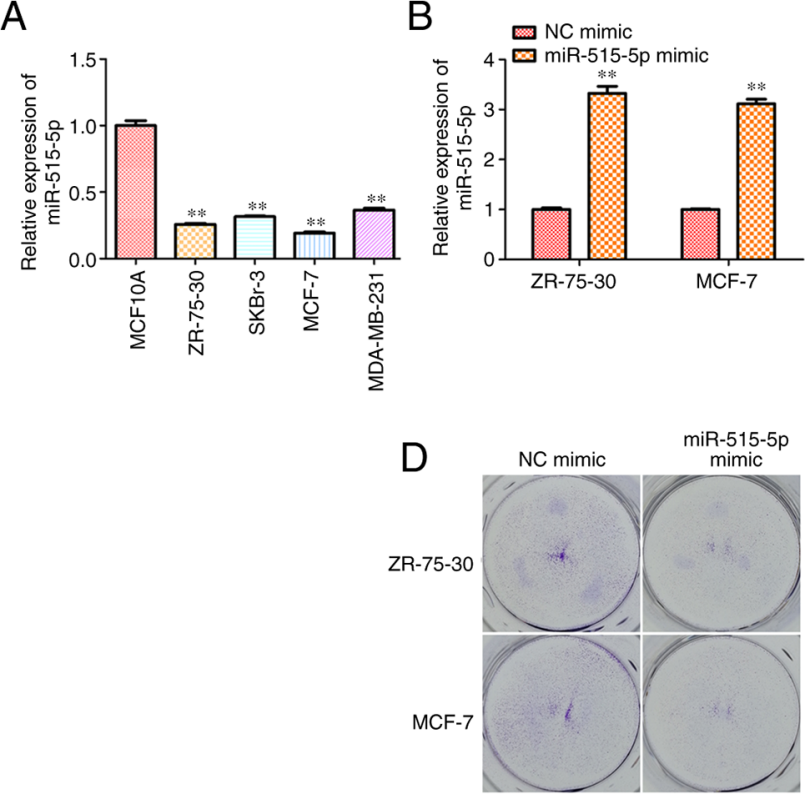

C
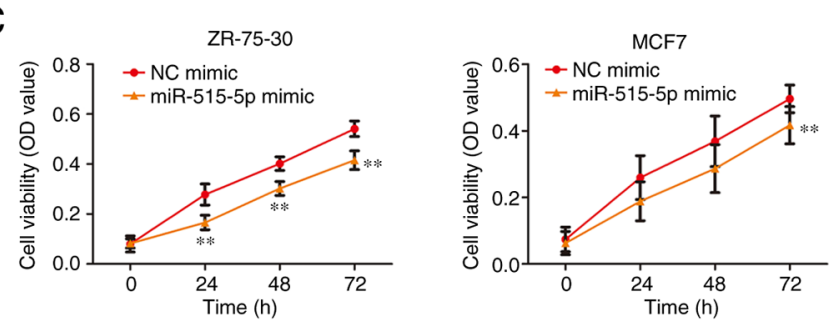

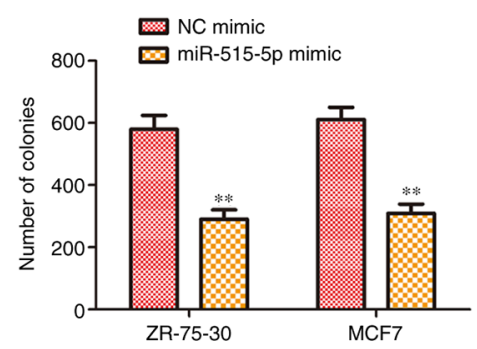

Figure 1. miR-515-5p overexpression inhibits the cell proliferation of MCF7 and ZR-75-30 cells. MCF7 and ZR-75-30 cells were transfected with miR-515-5p or NC mimics. (A) RT-qPCR was used to measure the expression of miR-515-5p in different human breast cancer cell lines MCF7, ZR-75-30, MDA-MB-231 and SKBr-3 and in the normal breast cell line MCF10A. (B) RT-qPCR was used to detect the expression of miR-515-5p in MCF7 and ZR-75-30 cells 48 h after transfection. (C) Cell Counting Kit-8 assay was performed on ZR-75-30 and MCF-7 cells to measure cell viability. (D) Colony formation assay was performed to measure cell proliferation. The data are presented as the mean \pm SD. ${ }^{* *} \mathrm{P}<0.01$ vs. NC mimic and MCF10A. miR, miRNA; NC, negative control; RT-qPCR, reverse transcription quantitative PCR; OD, optical density.

Next, data from the flow cytometric assay suggest that the miR-515-5p mimic significantly increased the percentage of cells at the $\mathrm{G}_{0} / \mathrm{G}_{1}$ phase and decreased the ratio of cells at $\mathrm{G}_{2} / \mathrm{M}$ phase in both MCF7 and ZR-75-30 cells ( $\mathrm{P}<0.01$; Fig. 2B). Finally, western blot analysis was performed to assess the expression of cell cycle-related proteins. The results showed that, miR-515-5p mimic transfection significantly reduced the expression levels of cyclin D1, CDK2 and increased the expression level of $\mathrm{p} 21$ proteins compared with those in cells transfected with the NC mimic $(\mathrm{P}<0.05$ and $\mathrm{P}<0.01$; Fig. $2 \mathrm{C})$. These results suggest that miR-515-5p can promote cell apoptosis whilst inducing cell cycle arrest at the $\mathrm{G}_{0} / \mathrm{G}_{1}$ phase in $\mathrm{BC}$.

miR-515-5p inhibits cell migration of MCF7 and ZR-75-30 cells. To further investigate the effect of miR-515-5p on the migration and invasion in BC cells, wound healing and Transwell assays were performed. Results from the wound healing assay indicated that miR-515-5p mimic transfection significantly decreased the wound closing abilities of MCF7 and ZR-75-30 cells compared with those in cells transfected with the NC mimic $(\mathrm{P}<0.01$; Fig. 3A), suggesting that miR-515-5p overexpression could inhibit cell migration. Similarly, Transwell assay results also demonstrated that miR-515-5p mimic transfection significantly inhibited cell invasion in MCF7 and ZR-75-30 cells compared with that in cells transfected with the $\mathrm{NC}$ mimic $(\mathrm{P}<0.05$ and $\mathrm{P}<0.01$; Fig. 3B). Subsequently western blot analysis showed that miR-515-5p mimic transfection decreased the expression levels of migration-related proteins MMP2, MMP9 and Cox-2 compared with those in cells transfected with the NC mimic $(\mathrm{P}<0.01$; Fig. 3C). Collectively, these results suggest that miR-515-5p overexpression decreased the migratory and invasive abilities of BC cells in vitro.
miR-515-5p inhibits CBX4 expression by directly binding to the 3'-UTR of CBX4. To explore the underlying mechanism of miR-515-5p in regulating BC progression, StarBase was used to screen for miR-515-5p target genes, where and CBX4 was found to harbor complementary binding sites for miR-515-5p (Fig. 4A). Therefore, a dual-luciferase reporter assay was used to verify this interaction. Consistent with bioinformatics analysis, the luciferase reporter assay results indicated that the miR-515-5p mimic could significantly downregulate the luciferase activity of CBX4 WT but not that of CBX4 Mut (P<0.01; Fig. 4B). Both RT-qPCR (Fig. 4C) and western blot analysis (Fig. 4D) results demonstrated that miR-515-5p mimic transfection could significantly decrease the mRNA and protein levels of CBX4 compared with those in cells transfected with the NC mimic $(\mathrm{P}<0.01)$. To confirm if CBX4 participates in $\mathrm{BC}$ progression, its expression level in BC cell lines MCF7, ZR-75-30, MDA-MB-231, SKBr-3 and the normal breast cell line MCF10A was compared using RT-qPCR. The results showed that the expression of CBX4 in human $\mathrm{BC}$ lines was significantly higher compared with that in the normal breast cell line $(\mathrm{P}<0.01 ;$ Fig. $4 \mathrm{E})$. These data suggest that miR-515-5p could inhibit the gene expression of CBX4 by directly binding to the 3'-UTR of CBX4 in BC cells.

Overexpression of $C B X 4$ reverses the effects of $m i R-515-5 p$ mimic in MCF7 and ZR-75-30 cells. To confirm the association between miR-515-5p and CBX4, MDA-MB-157 cells were co-transfected with miR-515-5p or NC mimics and Lv-CBX4 or Lv-NC. RT-qPCR data showed that Lv-CBX4 transfection could significantly upregulate the expression of CBX4 in MCF7 and ZR-75-30 cells compared with that in cells transfected with the Lv-NC $(\mathrm{P}<0.01$; Fig. 5A). To test the effect of the overexpression of CBX4 in BC cells viability, CCK-8 assay was conducted. The 

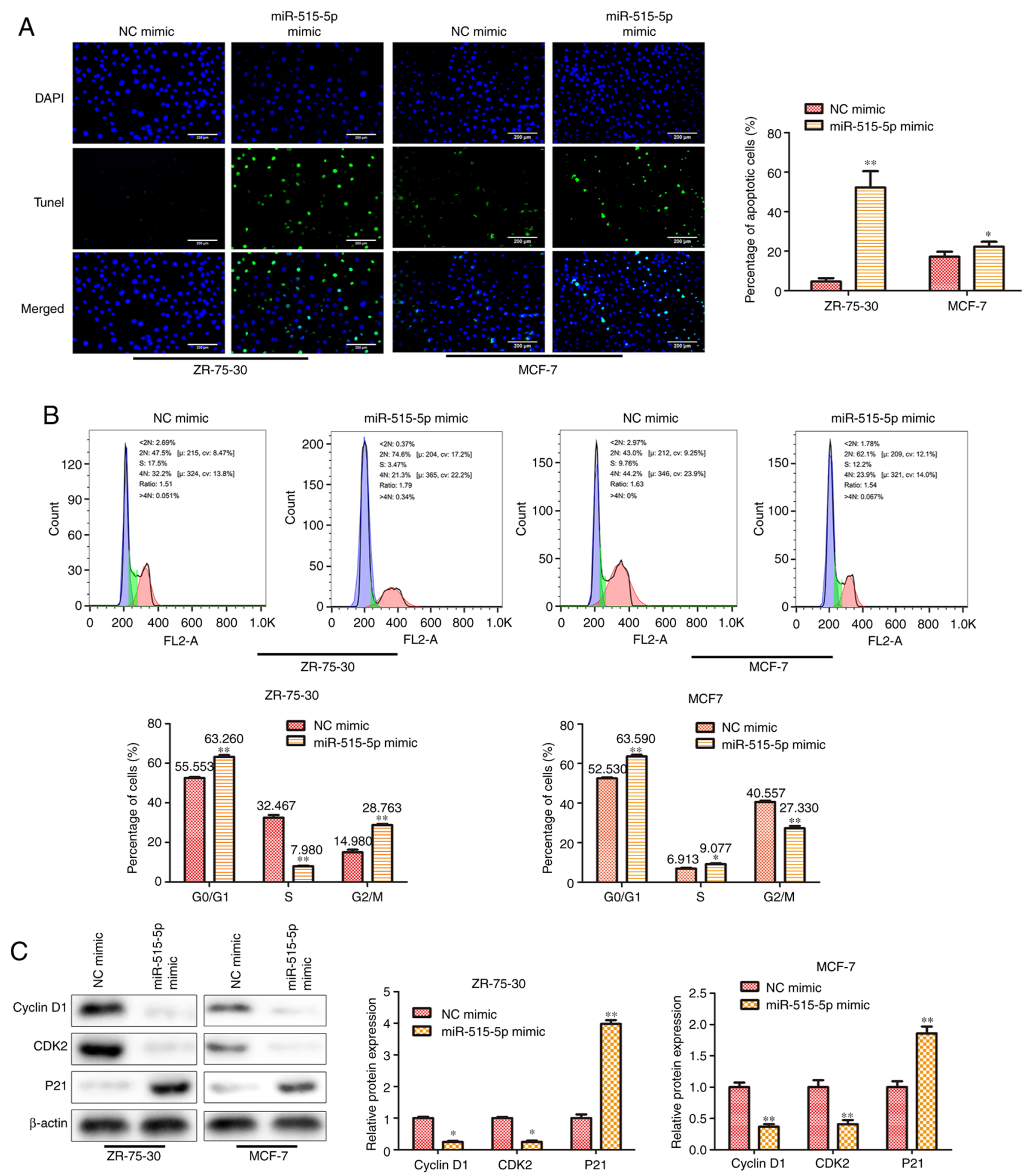

Figure 2. miR-515-5p overexpression facilitates cell apoptosis and induces cell cycle arrest at the $\mathrm{G}_{0} / \mathrm{G}_{1}$ phase in MCF7 and ZR-75-30 cells. MCF7 and ZR-75-30 cells were transfected with miR-515-5p mimic or the NC mimic. (A) TUNEL assay was performed to assess cell apoptosis. Scale bars, 200 $\mu \mathrm{m}$. (B) Flow cytometric assay was performed to assess cell cycle progression. (C) Western blot analysis was used to assess the expression of cyclin D1, CDK2 and 21 proteins. The data are presented as the mean $\pm \mathrm{SD}$. ${ }^{* *} \mathrm{P}<0.01$ and ${ }^{*} \mathrm{P}<0.05$ vs. NC mimic. miR, miRNA; NC, negative control; CDK2, cyclin dependent kinase 2; PCNA, proliferating cell nuclear antigen; P21, cyclin-dependent kinase inhibitor; <2N, $\mathrm{G}_{0}$ phase; $\mathrm{S}, \mathrm{S}$ phase; $4 \mathrm{~N}, \mathrm{G}_{2} / \mathrm{M}$.

results showed that co-transfection with miR-515-5p mimic and Lv-CBX4 could significantly increase the viability of MCF7 and ZR-75-30 cells compared with that in cells co-transfected with the miR-515-5p mimic and Lv-NC ( $<<0.05$; Fig. 5B). Colony formation assay results showed that $\mathrm{Lv}-\mathrm{CBX} 4$ co-transfection could promote the colony formation of MCF7 and ZR-75-30 cells transfected with miR-515-5p mimic, as compared with that of cells transfected with the Lv-NC and the miR-515 mimic $(\mathrm{P}<0.05$; Fig. $5 \mathrm{C})$. TUNEL assay results indicated that Lv-CBX4 co-transfection could inhibit the apoptosis of MCF7 and ZR-75-30 cells transfected with the miR-515-5p mimic compared with that in cell co-transfected with Lv-NC and 

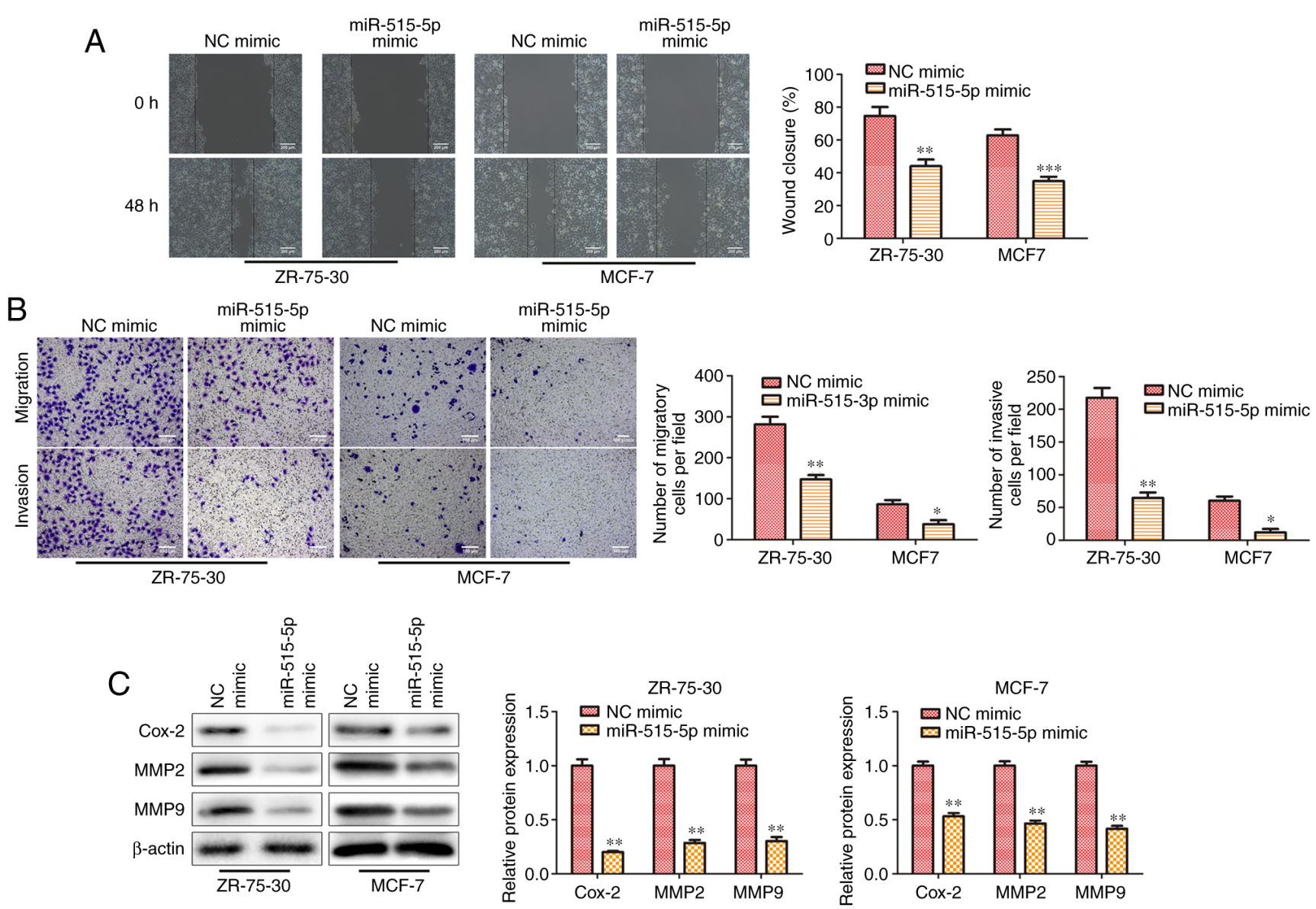

Figure 3. miR-515-5p inhibits cell migration in MCF7 and ZR-75-30 cells. MCF7 and ZR-75-30 cells were transfected with miR-515-5p mimic or inhibitor. (A) Wound healing assay was performed to assess cell migration. Scale bar, $200 \mu \mathrm{m}$. (B) Transwell assay was performed to assess cell migration and invasion. Scale bar, $100 \mu \mathrm{m}$. (C) Western blot analysis was performed to assess the protein expression levels of Cox-2, MMP2 and MMP9. The data are presented as the mean \pm SD. ${ }^{* * *} \mathrm{P}<0.001,{ }^{* *} \mathrm{P}<0.01$ and ${ }^{*} \mathrm{P}<0.05$ vs. NC mimic. miR, miRNA; Cox-2, prostaglandin-endoperoxide synthase 2 ; NC, negative control.
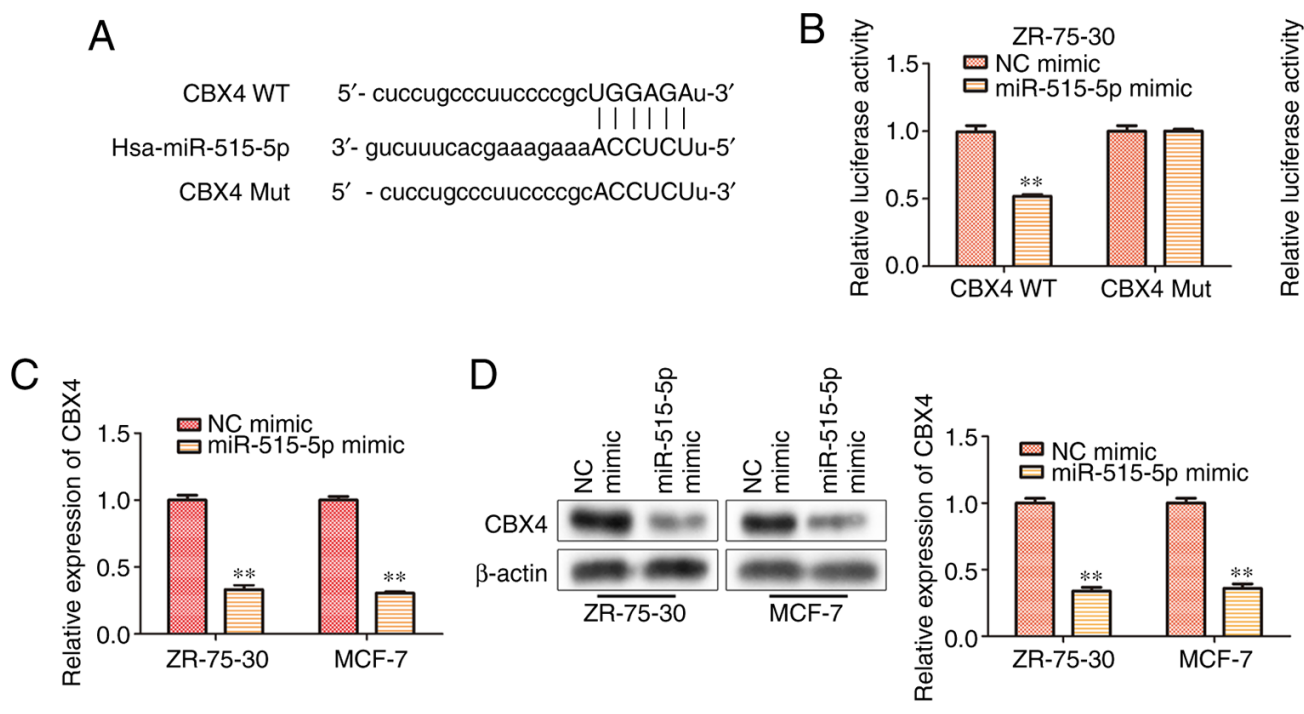

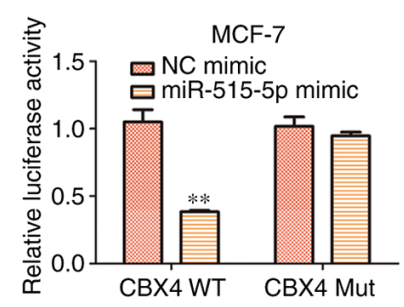

$\mathrm{E}$

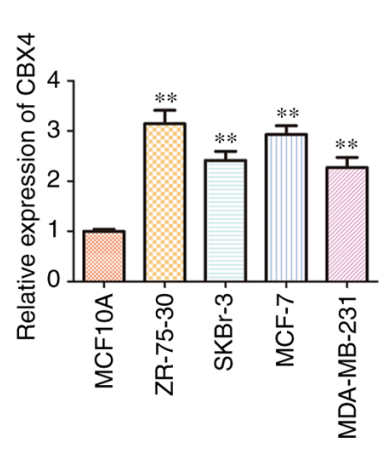

Figure 4. CBX4 serves as a direct miR-515-5p target in MCF7 and ZR-75-30 cells. (A) The putative binding sites between CBX4 and miR-515-5p was predicted using StarBase. (B) Dual-luciferase reporter assay was performed to assess the relationship between miR-515-5p and CBX4 in ZR-75-30 and MCF-7 cells. (C) RT-qPCR was performed to measure the mRNA expression of CBX4. (D) Western blot analysis was performed to measure the protein expression of CBX4 in MCF7 and ZR-75-30 cells transfected with miR-515-5p mimic. (E) RT-qPCR was performed to measure the mRNA expression of CBX4 in different human breast cancer cell lines MCF7, ZR-75-30, MDA-MB-231 and SKBr-3 and in the normal breast cell line MCF10A. The data are presented as the mean \pm SD. ${ }^{* *} \mathrm{P}<0.01$ vs. NC mimic and MCF10A. CBX4, polycomb chromobox 4; miR, miRNA; NC, negative control; Mut, mutant; WT, wild-type; RT-qPCR, reverse transcription quantitative PCR. 
A

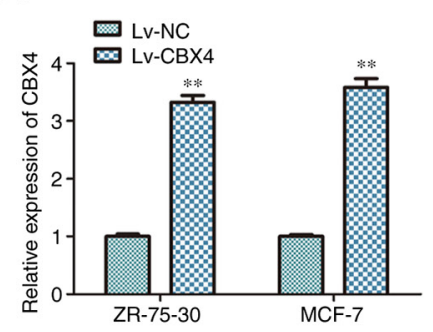

B

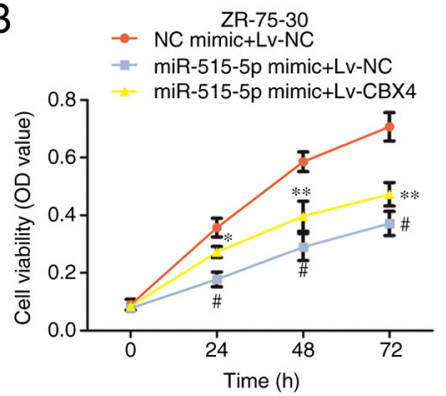

MCF-7

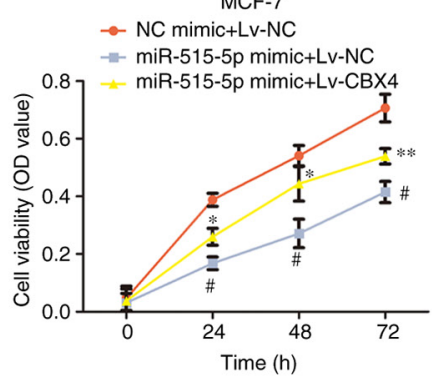

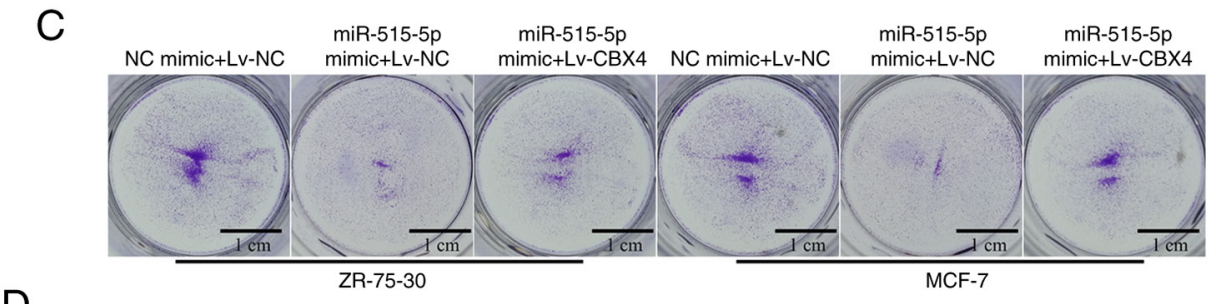

D

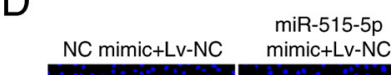

miR-515-5p

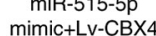

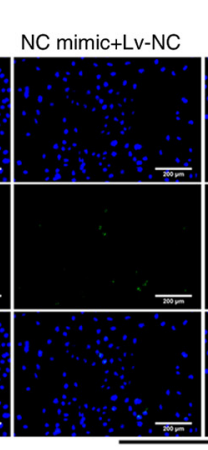

$\frac{1}{m-1}$
miR-515-5p mimic+Lv-NC

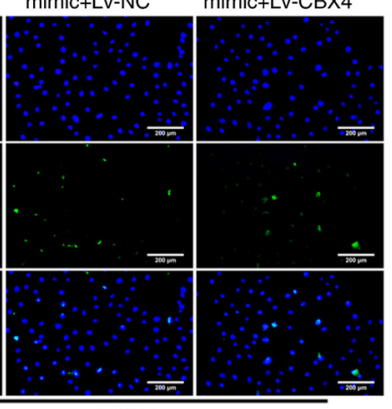

MCF-7

E
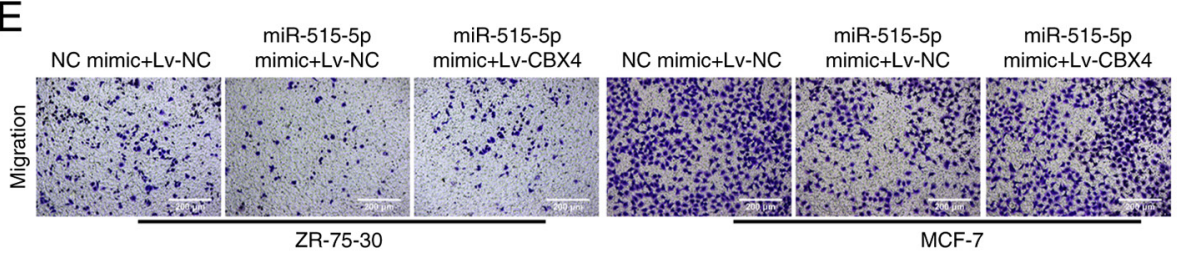
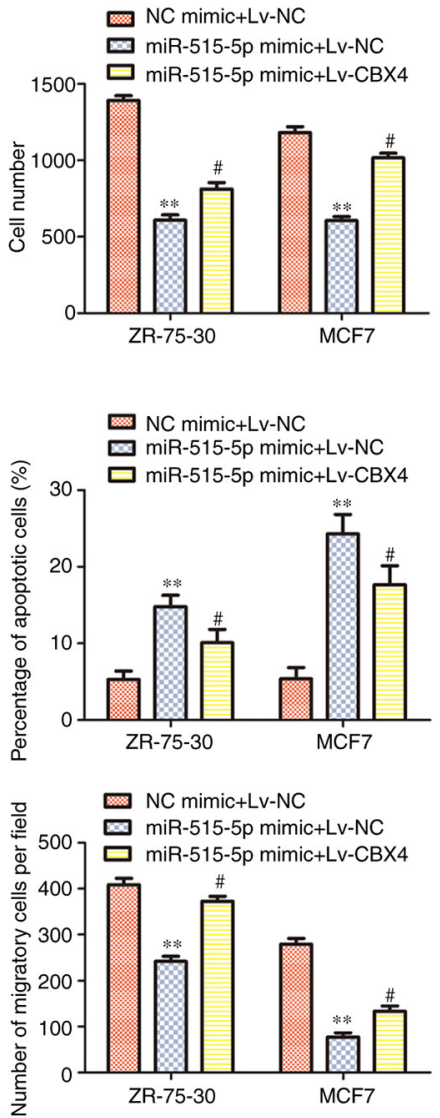

Figure 5. CBX4 overexpression reverses the effects of miR-515-5p overexpression in MCF7 and ZR-75-30 cells. (A) RT-qPCR was performed to assess the expression of CBX4 after Lv-CBX4 transfection. ${ }^{* *} \mathrm{P}<0.01$ vs. Lv-NC. (B-E) MCF7 and ZR-75-30 cells were co-transfected with the miR-515-5p mimic or NC mimic and Lv-CBX4 or Lv-NC. (B) Cell Counting Kit-8 assay was used to measure cell viability after co-transfection. (C) Colony formation assay was performed to assess cell proliferation. (D) TUNEL assay was performed to assess cell apoptosis. Scale bar, $200 \mu \mathrm{m}$. (E) Transwell assay was performed to assess cell migration. Scale bar, $200 \mu \mathrm{m}$. The data are presented as the mean $\pm \mathrm{SD}$. ${ }^{*} \mathrm{P}<0.05,{ }^{* *} \mathrm{P}<0.01$ vs. NC mimic $+\mathrm{Lv}-\mathrm{NC} ;{ }^{*} \mathrm{P}<0.05$ vs. miR-515-5p mimic + Lv-NC. CBX4, polycomb chromobox 4; NC, negative control; miR, miRNA; RT-qPCR, reverse transcription quantitative PCR.

miR-515 ( $\mathrm{P}<0.05$ and $\mathrm{P}<0.01$; Fig. 5D). Finally, Transwell assay data revealed that $\mathrm{Lv}-\mathrm{CBX} 4$ co-transfection could promote the migration of MCF7 and ZR-75-30 cells transfected with the miR-515-5p mimic compared with that in cells co-transfected with Lv-NC and miR-515-5p mimic $(\mathrm{P}<0.05$ and $\mathrm{P}<0.01$; Fig. 5E). These results suggest that the overexpression of $\mathrm{CBX} 4$ can partially reverse the effects of miR-515-5p overexpression on $\mathrm{BC}$ cell downregulation.

\section{Discussion}

$\mathrm{BC}$ is the leading cause of cancer-related mortality in women worldwide (1). Since BC is a multifactorial disease, unraveling the molecular changes associated with this type of cancer can potentially provide preventative and therapeutic strategies for this disease $(3,16)$. In $\mathrm{BC}$, a number of miRNAs, such as miR-148b, miR-376c, miR-409-3p and miR-801 have been identified as potential therapeutic targets $(17,18)$. In the present study, miR-515-5p expression was found to be downregulated in BC cell lines. Since the expression of miR-515-5p was the lowest in MCF7 and ZR-75-30 cells out of all BC cell lines tested, these two cell lines were selected to be models for further study. It was found that miR-515-5p overexpression inhibited the proliferation, migration and invasion of MCF7 and ZR-75-30 cells by suppressing the expression of CBX4. This preliminary study indicated that miR-515-5p may be a promising candidate for BC treatment.

miRNAs serve important roles in the onset, progression and metastasis of cancer by regulating the stability of target mRNAs or by inhibiting their translation (19). For 
example, miR-107 could inhibit autophagy, proliferation and migration in BC cells (MDA-MB-231, MDA-MB-453) by targeting high mobility group box 1 protein (20). There are numerous studies on the association between miR-515-5p and cancer. For instance, low miR-515-5p levels were found to be correlated with poor survival in samples from patients with gastric cancer on The Cancer Genome Atlas database (21). In addition, high miR-515-5p expression was correlated with increased survival of patients with $\mathrm{BC}$, such that miR-515-5p can control cancer cell migration by regulating microtubule affinity regulating kinase 4 (22). In BC, miR-515-5p was significantly downregulated in estrogen receptor (ER)-positive compared with that in ER-negative BC (23). Furthermore, miR-515-5p was previously found to partly modulate the proliferation of $\mathrm{BC}$ cells by regulating the Wnt pathway (23).

The present data showed that increasing the expression of miR-515-5p inhibited the proliferation of MCF7 and ZR-75-30 cells by facilitating cell apoptosis whilst arresting the cell cycle at the $G_{0} / G_{1}$ phase. Western blot analysis confirmed that the expression of cyclin D1, CDK2 that involved in $\mathrm{G}_{0} / \mathrm{G}_{1}$ phase were decreased and $\mathrm{p} 21$ proteins were increased by transfection with the miR-515-5p mimic. These findings were also supported by the observations the migration and invasion-associated protein expression of Cox-2, MMP2 and MMP9 were decreased by miR-515-5p mimic transfection. Subsequently, CBX4 was predicted by StarBase to be a direct target of miR-515-5p, which was further validated by luciferase report assays to demonstrate that miR-515-5p interacts directly with the 3'UTR of CBX4.

CBX4, also known as hPC2 or NBP16, is a canonical component of the polycomb repressive complex 1 , which is associated with a variety of tumors (24). CBX4 is directly involved in the DNA damage response pathway and regulates DNA modification, stability and terminal repair (24). CBX4 has been found to promote proliferation and metastasis in lung cancer (25) and hepatocellular carcinoma (26). CBX4 has also been reported to mediate miR-129-5p-induced inhibition of cell proliferation in BC (27). The present results suggest that miR-515-5p overexpression can decrease the expression of CBX4 in MCF7 and ZR-75-30 cells by directly interacting with the 3'UTR of CBX4. Additionally, overexpression of CBX4 reversed the effects of miR-515-5p on the proliferation, migration and invasion of MCF7 and ZR-75-30 cells. CBX4 has been reported to be involved in the small ubiquitin-like modifier (SUMO) modification of DNA methyltransferase 3A, PR domain containing 16, $B$ cell-specific moloney murine leukemia virus integration site 1 and hypoxia-induced factor- $1 \alpha$, as a SUMO E3 ligase (24,28-30). Therefore, miR-515-5p could mediate the SUMO modification states of proteins in breast cancer cells by targeting CBX4.

In conclusion, the present study demonstrated the function of miR-515-5p in MCF7 and ZR-75-30 cells as a breast cancer model. Specifically, miR-515-5p could regulate the cell viability and proliferation of $\mathrm{BC}$ cells by targeting CBX4, thereby inhibiting the migration and invasion of $\mathrm{BC}$ cells. The present study promoted the understanding of the mechanism via which miR-515-5p regulates the progression and metastasis of BC.

\section{Acknowledgements}

Not applicable.

\section{Funding}

The present study was supported by The Tianjin Municipal Education Commission Scientific Research Plan Project (grant no. 2020KJ145).

\section{Availability of data and materials}

The datasets used and/or analyzed during the current study are available from the corresponding author on reasonable request.

\section{Authors' contributions}

PYT and LJW designed the study and performed the experiments. PYT and YSW analyzed the data. LJW and PYT confirm the authenticity of all the raw data. All authors read and approved the final version of this manuscript.

\section{Ethics approval and consent to participate}

Not applicable.

\section{Patient consent for publication}

Not applicable.

\section{Competing interests}

The authors declare that they have no competing interests.

\section{References}

1. DeSantis CE, Ma J, Gaudet MM, Newman LA, Miller KD, Goding Sauer A, Jemal A and Siegel RL: Breast cancer statistics, 2019. CA Cancer J Clin 69: 438-451, 2019.

2. Zhang ML, Peng P, Wu CX, Gong YM, Zhang SW, Chen WQ and Bao PP: Report of breast cancer incidence and mortality in China registry regions, 2008-2012. Zhonghua Zhong Liu Za Zhi 41: 315-320, 2019 (In Chinese).

3. Wu H, Wang Q, Zhong H, Li L, Zhang Q, Huang Q and Yu Z: Differentially expressed microRNAs in exosomes of patients with breast cancer revealed by next-generation sequencing. Oncol Rep 43: 240-250, 2020.

4. Rossing M, Sørensen CS, Ejlertsen B and Nielsen FC: Whole genome sequencing of breast cancer. APMIS 127: 303-315, 2019.

5. Lytle JR, Yario TA and Steitz JA: Target mRNAs are repressed as efficiently by microRNA-binding sites in the 5' UTR as in the 3' UTR. Proc Natl Acad Sci USA 104: 9667-9672, 2007.

6. Ma C, Miao C, Wang C, Song F and Luo M: PELP1 is a novel oncogene in gastric tumorigenesis and negatively regulated by miR-15 family microRNAs. Cancer Biomark 26: 1-9, 2019.

7. Zhang C, Liu J, Tan C, Yue X, Zhao Y, Peng J, Wang X, Laddha SV, Chan CS, Zheng S, et al: microRNA-1827 represses MDM2 to positively regulate tumor suppressor p53 and suppress tumorigenesis. Oncotarget 7: 8783-8796, 2016.

8. Kim S, Lee E, Jung J, Lee JW, Kim HJ, Kim J, Yoo HJ, Lee HJ, Chae SY, Jeon SM, et al: microRNA-155 positively regulates glucose metabolism via PIK3R1-FOXO3a-cMYC axis in breast cancer. Oncogene 37: 2982-2991, 2018.

9. Shao B, Wang X, Zhang L, Li D, Liu X, Song G, Cao H, Zhu J and $\mathrm{Li} \mathrm{H}$ : Plasma microRNAs predict chemoresistance in patients with metastatic breast cancer. Technol Cancer Res Treat 18: $1533033819828709,2019$. 
10. Hromadníková I, Kotlabová K, Jirásek JE and Doucha J: Detection of placenta-specific microRNAs in maternal circulation. Ceska Gynekol 75: 252-256, 2010 (In Czech).

11. Zheng J, Sadot E, Vigidal JA, Klimstra DS, Balachandran VP, Kingham TP, Allen PJ, D'Angelica MI, DeMatteo RP, Jarnagin WR and Ventura A: Characterization of hepatocellular adenoma and carcinoma using microRNA profiling and targeted gene sequencing. PLoS One 13: e0200776, 2018.

12. Zhang X, Zhou J, Xue D, Li Z, Liu Y and Dong L: MiR-515-5p acts as a tumor suppressor via targeting TRIP13 in prostate cancer. Int J Biol Macromol 129: 227-232, 2019.

13. Li J, Tang Z, Wang H, Wu W, Zhou F, Ke H, Lu W, Zhang S, Zhang Y, Yang S, et al: CXCL6 promotes non-small cell lung cancer cell survival and metastasis via down-regulation of miR-515-5p. Biomed Pharmacother 97: 1182-1188, 2018.

14. Chen Y, Du J, Wang Y, Shi H, Jiang Q, Wang Y, Zhang H, Wei Y, Xue W, Pu Z, et al: MicroRNA-497-5p induces cell cycle arrest of cervical cancer cells in s phase by targeting CBX4. Onco Targets Ther 12: 10535-10545, 2019.

15. Rodriguez LG, Wu X and Guan JL: Wound-healing assay. Methods Mol Biol 294: 23-29, 2005.

16. Das PK, Siddika MA, Asha SY, Aktar S, Rakib MA, Khanam JA, Pillai $S$ and Islam F: MicroRNAs, a promising target for breast cancer stem cells. Mol Diagn Ther 24: 69-83, 2020.

17. CukK,Zucknick M,Heil J, Madhavan D, Schott S, Turchinovich A Arlt D, Rath M, Sohn C, Benner A, et al: Circulating microRNAs in plasma as early detection markers for breast cancer. Int J Cancer 132: 1602-1612, 2013.

18. Bahrami A, Aledavood A, Anvari K, Hassanian SM, Maftouh M, Yaghobzade A, Salarzaee O, ShahidSales S and Avan A: The prognostic and therapeutic application of microRNAs in breast cancer: Tissue and circulating microRNAs. J Cell Physiol 233: 774-786, 2018

19. Hafez MM, Hassan ZK, Zekri AR, Gaber AA, Al Rejaie SS, Sayed-Ahmed MM and Al Shabanah O: MicroRNAs and metastasis-related gene expression in Egyptian breast cancer patients Asian Pac J Cancer Prev 13: 591-598, 2012.

20. Ai H, Zhou W, Wang Z, Qiong G, Chen Z and Deng S: microRNAs-107 inhibited autophagy, proliferation, and migration of breast cancer cells by targeting HMGB1. J Cell Biochem: Dec 2, 2018 (Epub ahead of print). doi: 10.1002/jcb.28157.

21. Wang D, Liu K and Chen E: LINC00511 promotes proliferation and invasion by sponging miR-515-5p in gastric cancer. Cell Mol Biol Lett 25: 4, 2020.
22. Pardo OE, Castellano L, Munro CE, Hu Y, Mauri F, Krell J, Lara R, Pinho FG, Choudhury T, Frampton AE, et al: miR-515-5p controls cancer cell migration through MARK4 regulation. EMBO Rep 17: 570-584, 2016.

23. Pinho FG, Frampton AE, Nunes J, Krell J, Alshaker H, Jacob J, Pellegrino L, Roca-Alonso L, de Giorgio A, Harding V, et al: Downregulation of microRNA-515-5p by the estrogen receptor modulates sphingosine kinase 1 and breast cancer cell proliferation. Cancer Res 73: 5936-5948, 2013.

24. Ismail IH, Gagné JP, Caron MC, McDonald D, Xu Z, Masson JY, Poirier GG and Hendzel MJ: CBX4-mediated SUMO modification regulates BMI1 recruitment at sites of DNA damage. Nucleic Acids Res 40: 5497-5510, 2012.

25. Hu C, Zhang Q, Tang Q, Zhou H, Liu W, Huang J, Liu Y, Wang Q, Zhang J, Zhou M, et al: CBX4 promotes the proliferation and metastasis via regulating BMI-1 in lung cancer. J Cell Mol Med 24: 618-631, 2020.

26. Tan C, Bei C, Zhu X,Zhang Y, Qin L and Tan S: Single nucleotide polymorphisms of CBX4 and CBX7 decrease the risk of hepatocellular carcinoma. Biomed Res Int 2019: 6436825, 2019.

27. Meng R, Fang J, Yu Y, Hou LK, Chi JR, Chen AX, Zhao Y and Cao XC: miR-129-5p suppresses breast cancer proliferation by targeting CBX4. Neoplasma 65: 572-578, 2018.

28. Chen Q, Huang L, Pan D, Zhu LJ and Wang YX: Cbx4 sumoylates Prdm16 to regulate adipose tissue thermogenesis. Cell Rep 22: 2860-2872, 2018.

29. Li B, Zhou J, Liu P, Hu J, Jin H, Shimono Y, Takahashi M and $\mathrm{Xu}$ G: Polycomb protein Cbx4 promotes SUMO modification of de novo DNA methyltransferase Dnmt3a. Biochem J 405: 369-378, 2007.

30. Li J, Xu Y, Long XD, Wang W, Jiao HK, Mei Z, Yin QQ, Ma LN, Zhou AW, Wang LS, et al: Cbx4 governs HIF-1 $\alpha$ to potentiate angiogenesis of hepatocellular carcinoma by its SUMO E3 ligase activity. Cancer Cell 25: 118-131, 2014.

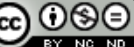

This work is licensed under a Creative Commons Attribution-NonCommercial-NoDerivatives 4.0 International (CC BY-NC-ND 4.0) License. 